\title{
Impurity Profiling of Baclofen Using Gradient HPLC-UV Method
}

\author{
Adrian Leistner $^{1}$. Ulrike Holzgrabe ${ }^{1}$ (D)
}

Received: 27 April 2021 / Revised: 13 July 2021 / Accepted: 2 August 2021 / Published online: 13 August 2021

(c) The Author(s) 2021

\begin{abstract}
The $\mathrm{GABA}_{\mathrm{B}}$ receptor agonist baclofen is a medication commonly used for the treatment of muscle spasticity. It is an amino acid and related to the neurotransmitter GABA. In this study, we developed a new, gradient high-performance liquid chromatography (HPLC) method for the impurity assessment of baclofen, which is appropriate for pharmacopoeial purposes. Since the impurities related to the synthesis pathway are acids, zwitterionic, or neutral, the method development is challenging. However, the separation of all components was achieved on a C18 stationary phase using a water-acetonitrile-trifluoroacetic acid gradient. A limit of detection (LOD) of at least $0.02 \%$ was registered for all specified impurities. Additionally, CAD detection was performed to detect potential impurities lacking off a chromophore. The baclofen batches analyzed are far more pure than expected. All impurities were found below the specification limit, and thus, they can be regarded as unspecified. Moreover, the required runtime could be significantly reduced compared to the current USP or Ph. Eur. method.
\end{abstract}

Keywords Impurity profiling $\cdot$ Baclofen $\cdot \mathrm{GABA}_{\mathrm{B}} \cdot$ Gradient HPLC-UV $\cdot \mathrm{CAD}$ detection $\cdot$ Pharmaceutical analysis

\section{Introduction}

Baclofen (Fig. 1) is widely used for the treatment of muscle spasticity often occurring with multiple sclerosis, degenerative traumatic spinal cord diseases, and paraplegic syndromes [1]. Additionally, baclofen is today off-label used to treat alcoholism [2]. Due to its structural similarity to the neurotransmitter $\gamma$-aminobutyric acid (GABA), baclofen is an agonist at the $\mathrm{GABA}_{\mathrm{B}}$ receptor in the spinal cord acting as muscle relaxant [3]. Commonly, 5-120 $\mathrm{mg}$ of the drug are administered orally per day [4], mostly in three-to-four equal dosages [5]. In addition, intrathecal infusions are on the market that are directly delivered to the cerebrospinal fluid space.

Since most of the impurities of an API are productionrelated, the synthesis pathways [3, 6-8] have to be studied carefully to identify potential impurities. The pathways for formation of potential impurities, named by some manufacturers, are displayed in Fig. 1.

The synthesis pathway (see the large box in Fig. 1) described by Keberle's group starts off with

Ulrike Holzgrabe

ulrike.holzgrabe@uni-wuerzburg.de

1 Institute for Pharmacy and Food Chemistry, University of Würzburg, Am Hubland, 97074 Würzburg, Germany 3-(4-chlorophenyl)pentanedioic acid, being impurity D, followed by the formation of the anhydride (1), which is converted to the imide using ammonia. The latter imide, being impurity $\mathrm{E}$, is hydrolyzed to either baclofen or to the amideacid side product impurity B. Impurity F occurs in case a wrong starting product was used, being the 3-(3,4-dichlorophenyl)pentanedioic acid (2), which was also converted to the respective glutarimide (4). Impurity A is an intramolecular cyclisation product and preferentially formed under dry and warm storage conditions [9]. Analogously, impurity $\mathrm{H}$ is formed out of impurity $\mathrm{C}$, which is a reaction product of two molecules of baclofen with carbonic acid. Of note, baclofen and the impurities $\mathrm{A}, \mathrm{B}, \mathrm{F}$, and $\mathrm{G}$ are each racemic compounds. In contrast, the impurities $\mathrm{C}$ and $\mathrm{H}$ have two stereocenters, resulting in three or four stereoisomers, respectively. Therefore, impurity $\mathrm{C}$ represents the diastereomeric mixture of a pair of enantiomers and of the meso compound, while impurity $\mathrm{H}$ is the diastereomeric mixture of two pairs of enantiomers.

The related substance test of the current monograph of baclofen, described in The Japanese Pharmacopoeia (JP XVII), makes use of isocratic reversed-phase chromatography with UV detection at $268 \mathrm{~nm}$ applying a simple $\mathrm{C} 18 \mathrm{col}-$ umn $(10 \mu \mathrm{m} ; 250 \times 4.0 \mathrm{~mm})$ and a mixture of methanol and diluted acetic acid as mobile phase [10]. However, the monograph does not specify any impurities, but limits a single 


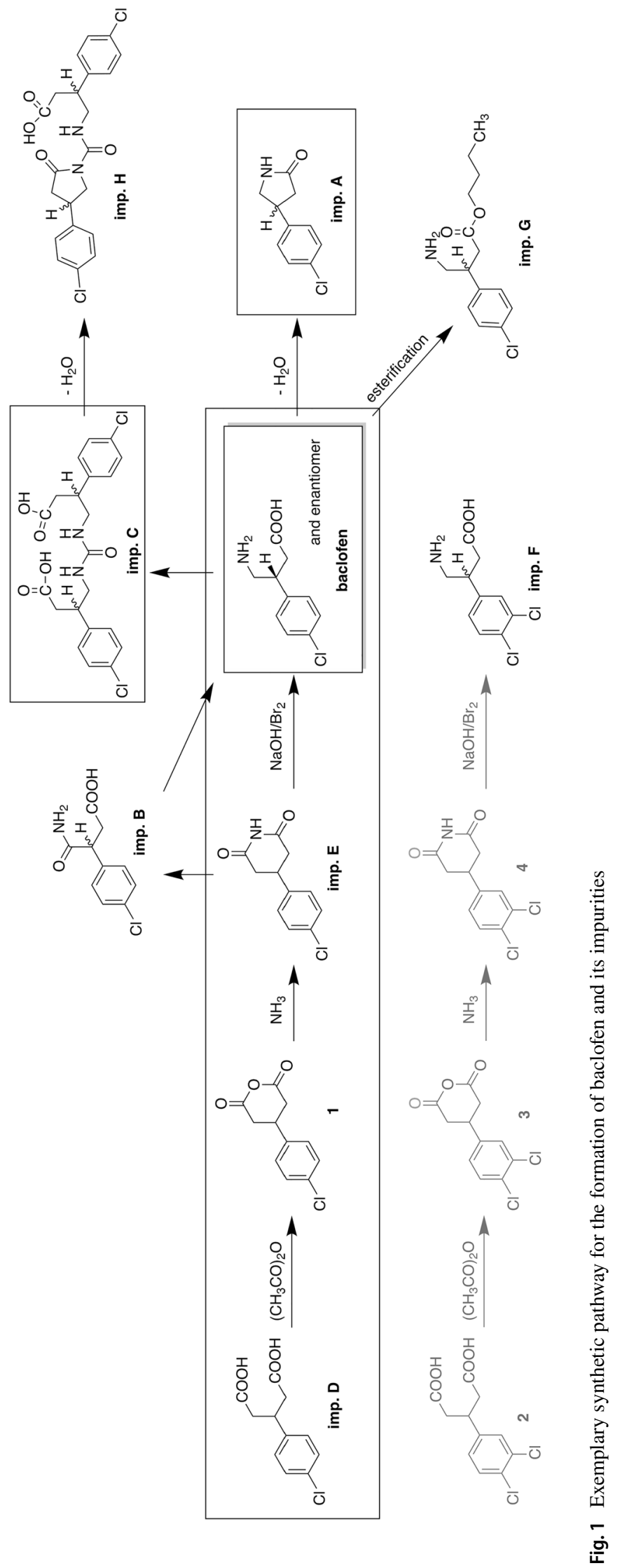


impurity at a level of $1.0 \%$ and the total sum of impurities at a level of $1.5 \%$, respectively. These limits are determined by evaluating the peak heights of peaks other than baclofen in the test solution in comparison to accordingly diluted baclofen solutions. The European Pharmacopoeia (Ph. Eur.) 10.0th ed. specifies and limits impurity A at a level of 1.0\% and a total of $2 \%$ using an isocratic ion-pair reversed-phase method [11]. Using the suitable LiChrospher ${ }^{\circledR} 100$ RP-18e $(5 \mu \mathrm{m}) 250 \times 4.0 \mathrm{~mm}$ column, baclofen is eluted after $4 \mathrm{~min}$ (cf. Figure S-1). According to the pharmacopoeial-related substances test, a total run time of 20 min being the fivefold of the retention time of baclofen is sufficient. In contrast, the United States Pharmacopeia (USP) 43 applies a gradient method by means of sodium pentanesulfonate as ion-pairing reagent and a mixture of acetonitrile and methanol using a column whose particle size was decreased to be $5 \mu \mathrm{m}$. Again, impurity A is limited to $1.0 \%$ and other impurities may be present at levels below $0.10 \%$, while in sum, a level of $2.0 \%$ impurity may not be exceeded [12].

Beside the different methods of the Pharmacopoeias, several methods for the content determination of baclofen are reported in the literature [13-15]. However, methods for impurity profiling of baclofen are quite rare. For the quantitation of baclofen and its impurities in injection formulations, an UPLC method was reported by Ga et al. being able to separate and quantify baclofen, imp. A and imp. B [16]. Elagawany et al. described a TLC method for the determination of at least two baclofen impurities [17], which can be considered as outdated, because of the typically low sensitivity of TLC.

Since the manufacturers announced additional impurities, the related substances test needs a revision. This newly developed method is a candidate to replace the current related substances test. Due to the daily dose of 30-75 mg, unspecified impurities should not exceed $0.1 \%$ [5, 18]. For the development of a new pharmacopoeial method, the impurities $\mathrm{A}$ and $\mathrm{C}$, displayed in the small boxes of Fig. 1, should be regarded as specified, because they occur potentially at levels higher than $0.1 \%$. Moreover, it can be assumed that the other impurities, being also related substances, will be detected as unspecified impurities by means of this newly developed method. Since only impurities A and $\mathrm{C}$ are available, a CAD detection was performed to find additional impurities without a chromophore.

\section{Experimental}

\section{Chemicals and Reagents}

Baclofen reference standards and the impurities A and $\mathrm{C}$ were obtained from the European Directorate for the Quality of Medicines \& HealthCare (EDQM), Strasbourg,
France. Trifluoroacetic acid (TFA) (>99\% purity), acetonitrile and methanol, HPLC grade ( $>99.9 \%$ purity), sodium pentanesulfonate ( $>99.0 \%$ purity), sodium hexanesulfonate ( $>98 \%$ purity), phosphoric acid and acetic acid were all of analytical grade ( $>99 \%$ purity) and were purchased from Sigma-Aldrich Chemie GmbH, (Darmstadt, Germany). Potassium dihydrogenphosphate for HPLC was purchased from VWR international GmbH (Darmstadt, Germany). Ultra-pure water was freshly produced by a water purification system from Merck Millipore (Darmstadt, Germany). All solutions were filtered through a $0.2 \mu \mathrm{m}$ PTFE filter (VWR international GmbH, Darmstadt, Germany).

\section{Apparatus}

HPLC measurements were performed on an Agilent 1100 modular chromatographic system consisting of an online vacuum degasser, a binary pump G1312A, an auto sampler G1313A, a thermostated column compartment G1316A, and a diode-array detector G1315B (Agilent Technologies Deutschland GmbH, Waldbronn, Germany). Agilent ChemStation ${ }^{\circledR}$ Rev. B03.02 software was used for data processing. The dwell volume of the Agilent system used for method development was $1.307 \mathrm{~mL}$. UV detection was performed at $225 \mathrm{~nm}$, except where otherwise stated.

For the experiments using CAD detection, an ESA Corona $^{\circledR}$ charged aerosol detector (ThermoFisher, Courtaboeuf, France) was linked with the HPLC system by a $0.25 \mathrm{~mm}$ internal diameter PEEK capillary and a $0.22 \mu \mathrm{m}$ stainless-steel inlet-frit. An ESA Nitrogen Generator (ThermoFisher, Courtaboeuf, France) was used to produce highly pure nitrogen (99.9\%). The gas inlet pressure was set to 35.0 psi. Filter was set to "none" and the electric current ranges to $100 \mathrm{pA}$.

To check the volatility of the compounds, experiments with different evaporation temperature settings $\left(30^{\circ} \mathrm{C}\right.$, $35^{\circ} \mathrm{C}, 40^{\circ} \mathrm{C}$ and $45^{\circ} \mathrm{C}$ ) and power function value setting 1.0 were performed on a Thermo Scientific Vanquish ${ }^{\mathrm{TM}}$ Flex modular chromatographic system (Thermo Fisher Scientific, Germering, Germany) consisting of a binary pump with online degasser, a thermostatted split sampler $\left(8^{\circ} \mathrm{C}\right)$, a thermostatted column compartment with passive pre-heater (both maintained at $35^{\circ} \mathrm{C}$ ), and a variable wavelength detector in-line with a Vanquish ${ }^{\mathrm{TM}}$ Horizon CAD. The CAD was supplied with nitrogen gas from an ESA nitrogen generator (Thermo Fisher Scientific) connected to the in-house compressed air system. The HPLC instrument was controlled, and runs were processed using the Chromeleon ${ }^{\circledR}$ Data System Version 7.2.6 software program (Thermo Fisher Scientific). 


\section{Chromatographic Procedure}

For the development of the new method, an end-capped octadecylsilyl silica gel for chromatography column Luna $^{\circledR} 3 \mu \mathrm{m}$ C18(2) $(100 \AA 150 \times 4.6 \mathrm{~mm}$, Phenomenex Ltd., Aschaffenburg, Germany) was used as stationary phase. The system was operated using gradient elution with a column oven temperature of $35^{\circ} \mathrm{C}$ and UV detection at $225 \mathrm{~nm}$. For the examination, mixtures containing acetonitrile, water, and TFA (20:79.95:0.05, v/v/v), mobile phase $\mathrm{A}$-and $(80: 19.95: 0.05, \mathrm{v} / \mathrm{v} / \mathrm{v})$, mobile phase B-were used: $0-2$ min: $5 \% \mathrm{~B} ; 2-3 \mathrm{~min}$ : $5-25 \% \mathrm{~B}$; 3-4 min: $25-35 \% \mathrm{~B} ; 4-13 \mathrm{~min}: 35 \% \mathrm{~B} ; 13-14 \mathrm{~min}$ : $35-5 \% \mathrm{~B} ; 14-16$ min: $5 \% \mathrm{~B}$, respectively. The flow rate was set to $1.0 \mathrm{~mL} \mathrm{~min}^{-1}$ and the injection volume was $20 \mu \mathrm{L}$.

\section{Preparation of Solutions}

\section{Sample Solution}

$45 \mathrm{mg}$ of baclofen were accurately weighed and dissolved in $100 \mathrm{~mL}$ of mobile phase $\mathrm{A}$.

\section{Stock Solutions}

Stock solutions ( $45 \mu \mathrm{g} \mathrm{mL}^{-1}$ ) of the respective impurities in mobile phase A were prepared for spiking the sample solution. Of note, impurity $\mathrm{C}$ was not available as the free acid, but as the dicyclohexylamine salt of impurity C only. Thus, a corrected mass (factor 1.8) was weighted and dissolved to obtain a stock solution of the required concentration.

\section{System Suitability Solution}

A system suitability solution of equal concentration level $\left(4.5 \mu \mathrm{g} \mathrm{mL}^{-1}\right)$ was prepared by spiking $100 \mu \mathrm{L}$ of the sample solution with $1000 \mu \mathrm{L}$ of each impurity stock solution and diluting this mix with mobile phase A to $10.0 \mathrm{~mL}$.

All solutions were stored at $5{ }^{\circ} \mathrm{C}$.

\section{Results and Discussion}

\section{HPLC Method Development}

First, the current USP and Ph. Eur. method were applied to check whether they are able to separate and detect the late eluting impurity $\mathrm{C}$, using the system suitability solution and the two batches available. The respective chromatograms of the system suitability solution are displayed in Figure S-1, and the batch results are listed in Table 1. The $\mathrm{Ph}$. Eur. method is unable to detect imp. $\mathrm{C}$ within a runtime of $20 \mathrm{~min}$ and at a sufficient LOQ, because the retention time was eightfold of the retention time of baclofen instead of fivefold as reported in the Ph. Eur. The LOQ of $0.69 \%$ is not sufficient to detect impurity $\mathrm{C}$ at a low level, and thus, this method needs further improvement. Using the USP method, impurity $\mathrm{C}$ can be evaluated, but again at a very long retention time at the end of the method, running into the risk of missing the peak if columns with a different carbon load are used. Additionally, the overall runtime of about $30 \mathrm{~min}$ for each of both pharmacopoeial methods is rather long.

Baclofen is an amino acid of zwitterionic character and would, thus, elute very early on a reversed-phase column without using ion-pairing reagents, while impurity $\mathrm{A}$ is neutral and impurity $\mathrm{C}$ is charged depending on the $\mathrm{pH}$. In particular, these different physico-chemical properties of the analytes are responsible for the need of gradient elution and ion-pairing reagents when a reversed-phase column is planned to use. Therefore, a standard end-capped octadecylsilyl silica gel for chromatography column was used to keep the system as simple as possible.

Because usage of longer chain ion-pairing reagents with low detection wavelength often causes unacceptable background noise, TFA was applied instead, which is additionally not critical at a detection wavelength of $>220 \mathrm{~nm}[19$, 20]. In addition, at low concentration levels, $\mathrm{pH}$ values of about 2 can easily be achieved. The column compartment and the autosampler were operated at $35^{\circ} \mathrm{C}$, while the flow rate was set to $1.0 \mathrm{~mL} \mathrm{~min}^{-1}$.

The UV absorption maximum of baclofen $(220 \mathrm{~nm})$ and its specified impurities $\mathrm{A}$ and $\mathrm{C}$ are quite similar. Since the baseline noise is borderline at this wavelength, the
Table 1 Results of two baclofen batches

\begin{tabular}{lclllllll}
\hline Impurity & \multicolumn{2}{l}{ Content [\%] batch \#1 } & & \multicolumn{3}{l}{ Content [\%] batch \#2 } \\
\cline { 2 - 3 } & New method & Ph. Eur & USP & & New method & Ph. Eur & USP \\
\hline Imp. at 7.3 min & 0.05 & n.a & n.a & - & n.a & n.a \\
Imp. A & $<0.05$ & 0.08 & 0.09 & & $<0.05$ & $<0.05$ & $<0.05$ \\
Imp. C & $<0.05$ & n.a & $<0.05$ & & 0.06 & $<0.05$ & 0.09 \\
Sum of impurities & 0.05 & 0.08 & 0.09 & & 0.06 & & 0 & 0.09 \\
\hline
\end{tabular}


experiments of the optimized method were performed at $225 \mathrm{~nm}$, as in the USP method.

Upon method development, the injection volume was optimized. Since the injection of $10 \mu \mathrm{L}$ of the sample solution did not achieve a sufficient LOQ, the mass on column had to be increased. Since the injection of a higher concentrated solution was not possible for solubility reason, $20 \mu \mathrm{L}$ were injected, which resulted in a satisfactory LOQ of at least $0.05 \%$.

Analogously, the chromatographic conditions, such as the temperature of the column compartment, the flow rate, and the TFA content, were optimized. Its influence on the separation can be seen in Fig. 2. Beside the TFA concentration, the variations have a small influence on the separation only. The latter shows the best separation used at a concentration level of $0.05 \%$.

As already stated, baclofen and its related substances are of different physico-chemical properties, and thus, gradient elution is necessary to guarantee elution within acceptable time. The starting conditions were selected for dissolution of baclofen and its impurities and additionally to avoid coelution of the injection peak and baclofen. A gradient was chosen to achieve sufficient resolution between potential impurities eluting between baclofen and imp. A and a total run time of less than 16 min.

CAD detection is especially utilized for substances lacking off a chromophore or those with a weak one, only. Since the CAD response is independent of physiochemical properties, it is suitable to look for known and unknown impurities. As at low levels, impurity $\mathrm{C}$ is not easy to quantify by means of UV detection correctly (shallow peak height and baseline noise), CAD detection experiments were performed. This was possible, because the final HPLC method is suitable for CAD due to the volatility of the mobile phase. In Fig. 3, the hyphenated detection of UV and CAD is shown for the system suitability solution. Interestingly, the solution of batch \#1 did not show any other impurity (see Fig. 4), which are expected to elute after baclofen due to their structure, while the solution of batch \#2 contained an unspecified impurity eluting close to impurity A. Chromatograms of both batches and the system suitability solution are displayed in the Supplementary Information (Figure S-2).

Of note, the comparison of UV and CAD detection revealed a substantial difference in peak height, which is due to the semi-volatility of impurity A within CAD detection (cf. Figure 5 and Figure S-3). Moreover, the counterion of impurity $\mathrm{C}$ being dicyclohexylamine is detected, but no additional impurity. Since a UV detection is the mostly used in quality assessment, the validation is performed using UV detection.

\section{Validation}

The method was validated with regard to specificity, linearity, range, precision, accuracy, LOD/LOQ, and robustness according to the guideline Q2(R1) of the International Council for Harmonisation of Technical Requirements for Pharmaceuticals for Human Use (ICH) [21].

Specificity The system suitability solution containing equal amounts $\left(4.5 \mu \mathrm{g} \mathrm{mL}^{-1}\right)$ of baclofen and its impurities $\mathrm{A}$ and $\mathrm{C}$ was used to assign the peaks. All impurities were baseline separated from baclofen and from each other (Fig. 3). Additionally, it was even possible to achieve a slight separation of the diastereomeric mixture of impurity $\mathrm{C}$.

Linearity and range To determine linearity and range, a calibration range of $0.05-0.40 \%$ for both impurities (eight
Fig. 2 Robustness study for the related substances method of baclofen

\section{Separation of baclofen and related substances}

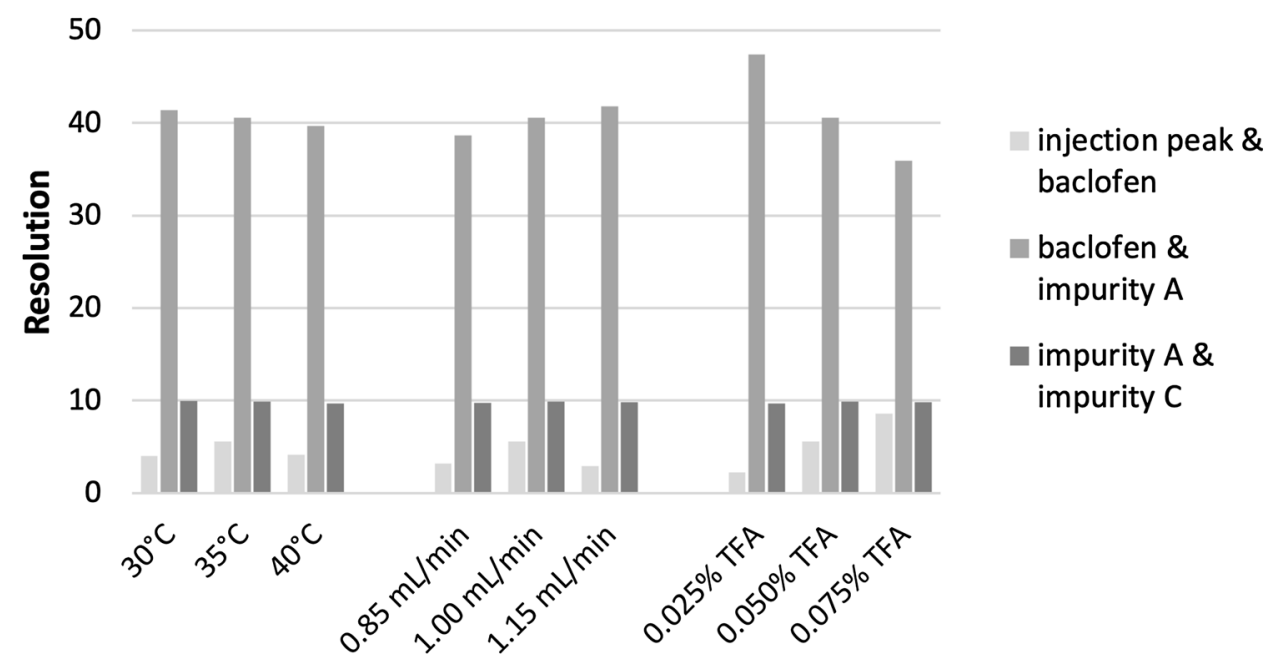




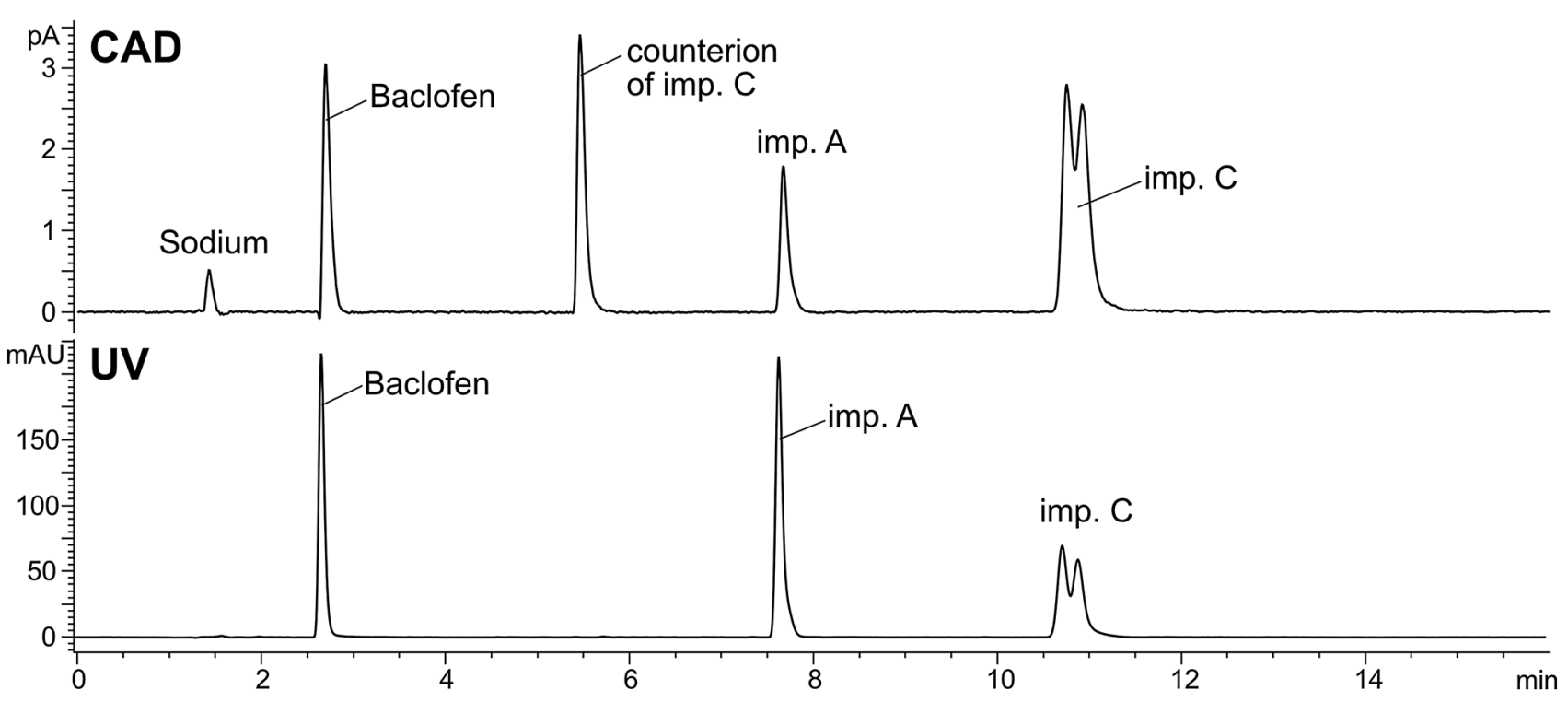

Fig. 3 A typical chromatogram obtained with the system suitability solution. Peak labeling: baclofen, impurity A and impurity C; column: Phenomenex Luna ${ }^{\circledR} 3 \mu \mathrm{m} \mathrm{C} 18(2) 100 \AA 150 \times 4.6 \mathrm{~mm}$; the chromatographic system was operated with a flow rate of $1.0 \mathrm{~mL}$ $\min ^{-1}$ using gradient elution at $35^{\circ} \mathrm{C}$, UV $(225 \mathrm{~nm})$ and CAD detection. Further chromatographic conditions for this gradient HPLC can be seen in the section "Chromatographic Procedure"

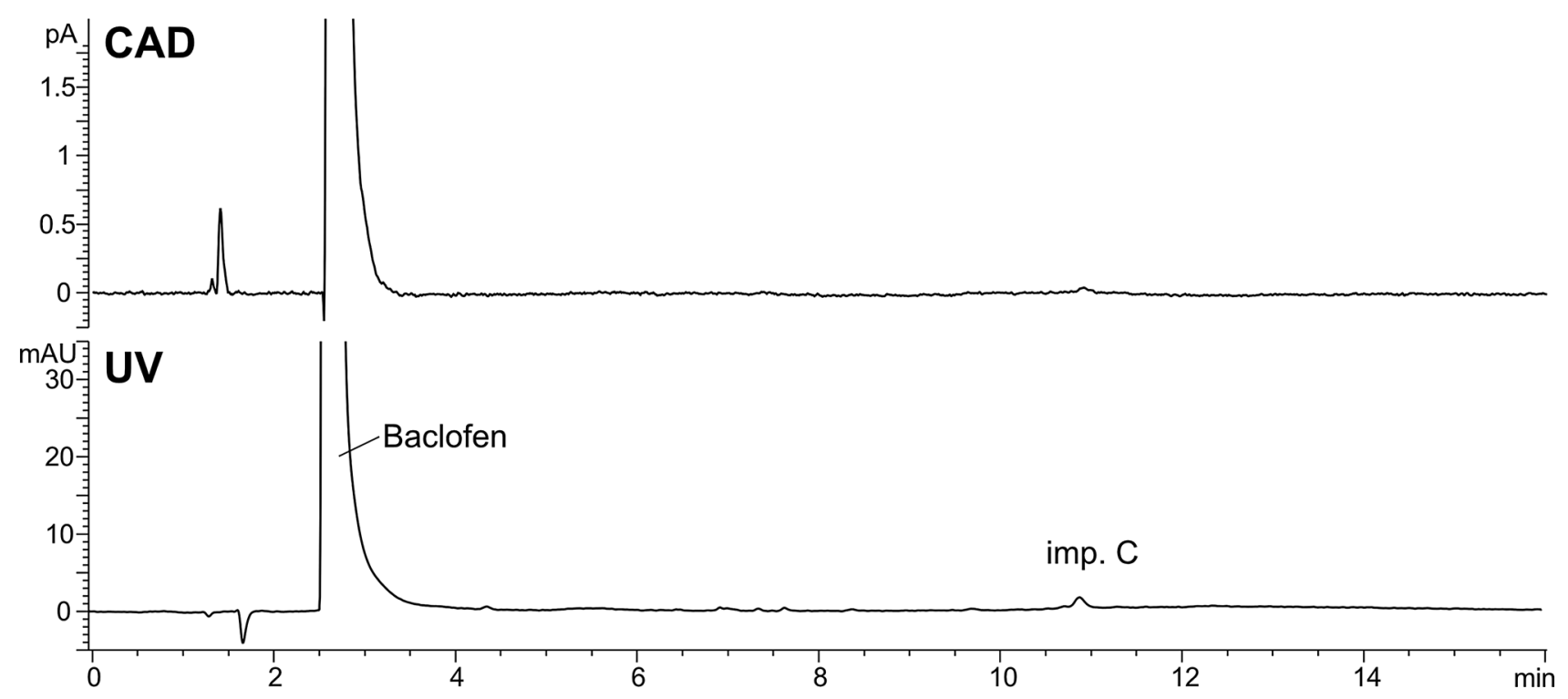

Fig. 4 Chromatogram obtained with a sample solution of batch \#1 by means of UV and CAD detection. Chromatographic conditions for this gradient HPLC can be seen in the section "Chromatographic Procedure"

concentration levels are equally distributed) was established (see Figure S-3).

As displayed in Table 2, the coefficient of determination $\left(R^{2}\right)$ was higher than 0.9995 for each calibration curve, and a relative standard deviation (RSD) on every level for both impurities below $4.76 \%$ was obtained (Supplementary Information Figure S-4).
Accuracy For the assessment of accuracy, spiked sample solutions were used. According to the Ph. Eur. 10 (chapter 2.2.46.) [11], a response factor has to be applied if it is out of the range $0.8-1.2$, for the correct calculation of the content of the impurities. The respective response factor can be obtained with the following equation, while $A_{i}$ represents the area of the peak due to the impurity, $A_{s}$ the area of the 
Fig. 5 Influence of the evaporation temperature on the peak area of the respective CAD signals

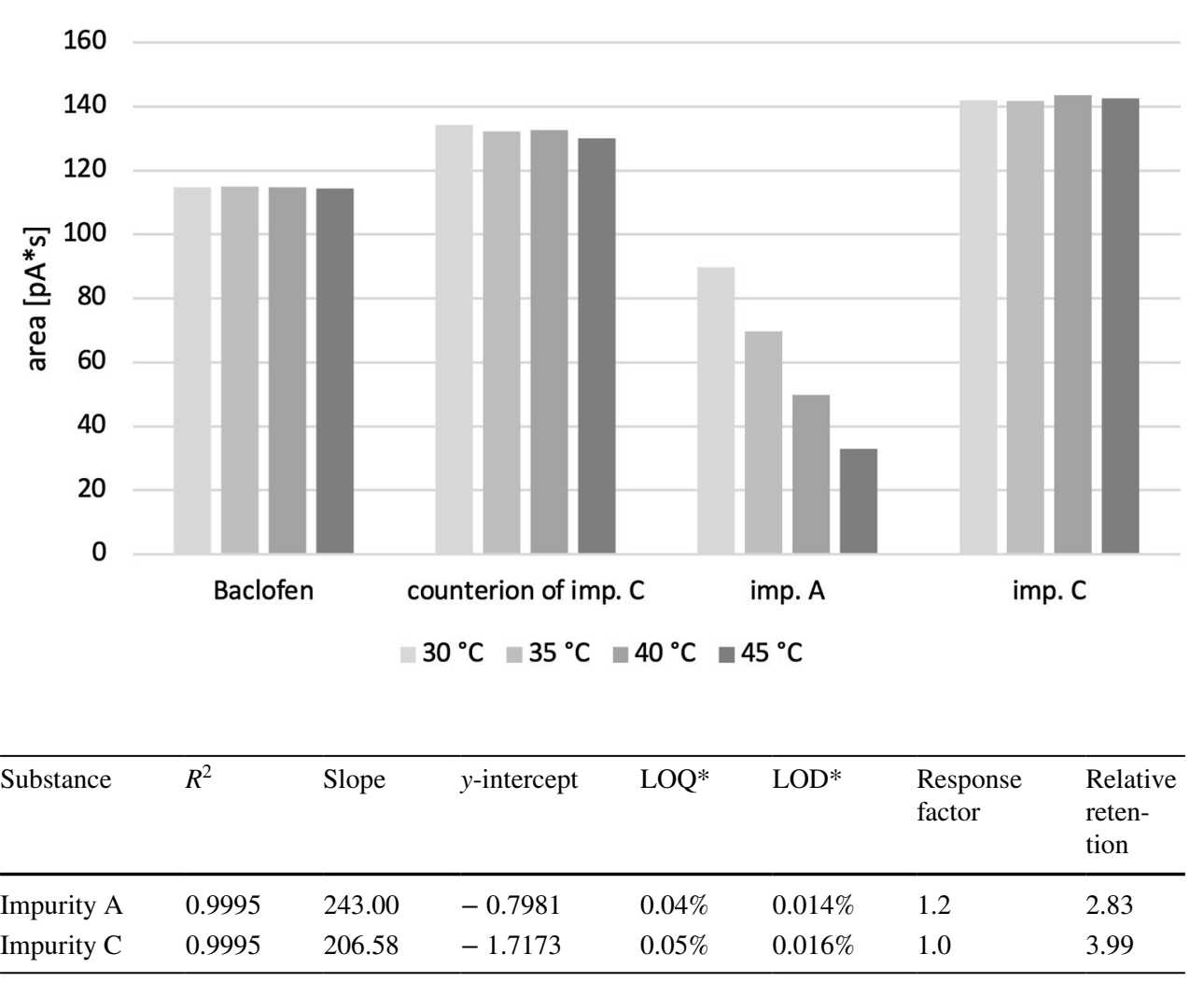

\begin{tabular}{llllllll}
\hline Substance & $R^{2}$ & Slope & $y$-intercept & LOQ* & LOD* & $\begin{array}{l}\text { Response } \\
\text { factor }\end{array}$ & $\begin{array}{l}\text { Relative } \\
\text { reten- } \\
\text { tion }\end{array}$ \\
\hline Impurity A & 0.9995 & 243.00 & -0.7981 & $0.04 \%$ & $0.014 \%$ & 1.2 & 2.83 \\
Impurity C & 0.9995 & 206.58 & -1.7173 & $0.05 \%$ & $0.016 \%$ & 1.0 & 3.99 \\
\hline
\end{tabular}

*In percent of the sample solutions' concentration
Table 2 Parameters of the linear regression of analyte concentration and peak area, response factors obtained from calibration, and the relative retention to baclofen for all impurities peak due to baclofen, $C_{s}$ the concentration of baclofen in milligrams per milliliter, and $C_{i}$ the concentration of the impurity in milligrams per milliliter:

response factor $=\frac{A_{i}}{A_{s}} \times \frac{C_{s}}{C_{i}}$

All response factors (Table 2) are within this range and no further correction is necessary. Recovery rates (cf. Figure S-5) were calculated at the lower end of the calibration curves, at the specification limit for imp. C $(0.15 \%)$ as well as on the upper end of the calibration curve and found between 96 and $111 \%(n=6$; RSD $=0.44-4.46 \%)$ on every level.

All batches contained at least one of the specified impurities at a very low level. For the assessment of repeatability and precision, two real batch samples, spiked with $0.25 \%$ of each impurity were used. The RSD intra-day was between 0.76 and $0.85 \%(n=6)$ and inter-day determined on 2 consecutive days between 0.75 and $1.16 \%(n=12)$, indicating a sufficient precision.

The formation rate of the lactam impurity A out of baclofen in aqueous solution is $\mathrm{pH}-$ dependent [9]. For solutions of low $\mathrm{pH}$ values as applied in the mobile phase, this process is supposed to be very slow. Nevertheless, sample solutions were stored at room temperature for 1 month to check its stability. Beside the approximate doubling of the content of imp. A., an increase of an additional unknown decomposition product at a very low level was observed. Therefore, all solutions were stored at $5{ }^{\circ} \mathrm{C}$ to ensure sufficient stability. Forced degradation studies reported in the literature confirm this observation. Ahuja reported a slow formation of impurity A, while dos Santos showed high stability of baclofen under forced degradation conditions [9, 22].

$L O D / L O Q$ Since baclofen is used in a daily dosage range of 5-120 mg [4], a reporting threshold for impurities is defined to be $0.05 \%$ according to chapter "Substances for Pharmaceutical use" of the European Pharmacopoeia [11, 18]. LODs and LOQs are calculated by means of the calibrations curves and with regard to ICH guideline Q2(R1) [21] using the following equations:

$\mathrm{LOD}=\frac{3.3 \sigma}{b} \quad \mathrm{LOQ}=\frac{10 \sigma}{b}$

with $\sigma$ being the standard deviation of the response and $b$ being the slope of the calibration curve, respectively [23]. As can be seen from Table 2, the LOQs meet the requirement of $0.05 \%$ for quality assessment.

Robustness To check the robustness of the method, relevant measuring parameters were varied in the following ranges: temperature of the column compartment $\pm 5^{\circ} \mathrm{C}$, flow 
rate $\pm 0.15 \mathrm{~mL} \mathrm{~min}^{-1}$, and TFA content $\pm 0.025 \%$ (v/v). As can be deduced from Fig. 2, most variations have a small influence on the separation of all components. Only the TFA content is critical.

System suitability To ensure system suitability, the pharmacopoeias make use of critical separation pair. However, a real critical peak pair does not exist for this method. Since it was one goal to have enough time space for potential impurities eluting between the main peak and imp. A, the most critical separation within this application is due to the injection peak and baclofen.

\section{Batch Results}

This new method was used to test two batches of baclofen (see Table 1). Both batches are very pure. Batch \#2 contains impurity A and an unspecified impurity at a very low level, while impurity $\mathrm{C}$ was below the detection limit. As can be seen from Figure $\mathrm{S}-2$, the unspecified impurity is detected by $\mathrm{UV}$ and $\mathrm{CAD}$, while imp. A is present at a UV-detectable level, only. The other batch contained a low amount of impurity $\mathrm{C}$, while impurity $\mathrm{A}$ is not detected at a level to be reported. Of note, this batch solution contains one of the diastereomers of impurity $\mathrm{C}$, only. According to the rules of the $\mathrm{Ph}$. Eur., only impurity $\mathrm{C}$ has to be regarded as specified.

A mass balance approach carried out confirms that $99.7 \%$ and $99.8 \%$ of the sample mass can be attributed to baclofen and its specified impurities, respectively.

\section{Conclusion}

Currently, the major pharmacopoeias are not harmonized with regard to the related substances test of baclofen. Moreover, some API manufacturers gave additional impurities without providing material. For one batch, neither the CAD nor the UV detection of the new method developed showed any other impurity beside $\mathrm{A}$ and $\mathrm{C}$, which can be detected by means of the new method at an LOD of at least $0.02 \%$. The other batch contained an unknown impurity at a level of $0.05 \%$. Taken together, baclofen is far more pure than described in all international pharmacopoeias; all impurities can be regarded as unspecified, because all of them were found to be below the disregard limit. To document the superiority of this newly developed method, further investigations could be made. The expected specificity for the currently not available potential impurities shown in the reaction scheme could be demonstrated and the purity of further batches (e.g., of the same and of other manufacturers) could be analyzed to confirm baclofen as a high-purity product.

Supplementary Information The online version contains supplementary material available at https://doi.org/10.1007/s10337-021-04079-y.
Acknowledgements Thanks are due to the Hanns Seidel Foundation and the German Federal Ministry of Education and Research (BMBF) for financial support.

Author contributions Conceptualization: $\mathrm{AL}$ and $\mathrm{UH}$; methodology: $\mathrm{AL}$ and $\mathrm{UH}$; formal analysis and investigation: $\mathrm{AL}$ and $\mathrm{UH}$; writingoriginal draft preparation: AL; writing - review and editing: UH; supervision: UH.

Funding Open Access funding enabled and organized by Projekt DEAL. Adrian Leistner received funding from the Hanns Seidel Foundation and the German Federal Ministry of Education and Research (BMBF).

Data Availability Not applicable.

Code Availability Not applicable.

\section{Declarations}

Conflict of Interest Not applicable.

Open Access This article is licensed under a Creative Commons Attribution 4.0 International License, which permits use, sharing, adaptation, distribution and reproduction in any medium or format, as long as you give appropriate credit to the original author(s) and the source, provide a link to the Creative Commons licence, and indicate if changes were made. The images or other third party material in this article are included in the article's Creative Commons licence, unless indicated otherwise in a credit line to the material. If material is not included in the article's Creative Commons licence and your intended use is not permitted by statutory regulation or exceeds the permitted use, you will need to obtain permission directly from the copyright holder. To view a copy of this licence, visit http://creativecommons.org/licenses/by/4.0/.

\section{References}

1. Steinhilber D, Schubert-Zsilavecz M, Roth HJ (2010) Medizinische chemie, 2nd edn. Deutscher Apotheker Verlag, Stuttgart

2. de Beaurepaire R et al (2019) The use of baclofen as a treatment for alcohol use disorder: a clinical practice perspective. Front Psychiatry. https://doi.org/10.3389/fpsyt.2018.00708R

3. Kent CN, Park C, Lindsley CW (2020) Classics in chemical neuroscience: baclofen. ACS Chem Neurosci 11:1740-1755. https:// doi.org/10.1021/acschemneuro.0c00254

4. Geisslinger G, Menzel S, Gudermann T, Hinz B, Ruth P, Mutschler E (2019) Mutschler arzneimittelwirkungen: pharmakologie-klinische pharmakologie-toxikologie. Hirzel Verlag

5. Novartis, Lioresal ${ }^{\circledR}$ 5-Gebrauchsinformation (2019) https:// www.novartis.de/system/files/product-info/051981_GI_Liore sal_3.pdf. Accessed 05 Feb 2021

6. Vardanyan RS, Hruby VJ (2006) 15. Muscle relaxants. In: Vardanyan RS, Hruby VJ (eds) Synthesis of essential drugs. Elsevier, Amsterdam, pp 209-218. https://doi.org/10.1016/B978-04445 2166-8/50015-7

7. Keberle H, Faigle JW, Wilhelm M (1964) Gamma-amino-beta(para-halophenyl)-butyric acids and their esters. U.S. Patent $3,471,548$

8. Jagtap A, Gharpure M, Shinde N, Patil N, Raut C, Krishnamurthy D (2017) A process for the preparation of baclofen, Piramal Enterprises Limited, Patent WO2017009753, https://worldwide. 
espacenet.com/publicationDetails/biblio?CC $=\mathrm{WO} \& \mathrm{NR}=20170$ 09753A1\&KC $=\mathrm{A} 1 \& \mathrm{FT}=\mathrm{D}$. Accessed $10 \mathrm{Jan} 2021$

9. Ahuja S, Florey K (ed) (1985) Analytical profiles of drug substances, vol 14. Academic Press, London, pp 527-548. https:// doi.org/10.1016/S0099-5428(08)60590-0

10. Ministry of Health, Labour and Welfare (2016) The Japanese pharmacopoeia, 17th ed. (JP XVII), Tokyo. https://www.mhlw. go.jp/file/06-Seisakujouhou-11120000-Iyakushokuhinkyoku/ JP17_REV_1.pdf. Accessed 20 Nov 2020.

11. Council of Europe: European Department for the Quality of Medicines (2020) European pharmacopeia, 10th edn. Council of Europe: European Department for the Quality of Medicines, Strasbourg

12. US Pharmacopeial Convention (2020) United States pharmacopeia 43. US Pharmacopeial Convention, Rockville

13. Dukova OA, Krasnov EA, Efremov AA (2015) Development of an HPLC method for determining baclofen. Pharm Chem J 48:687-689. https://doi.org/10.1007/s11094-015-1172-5

14. Rustum AM (1989) Simple and rapid reversed-phase high-performance liquid chromatographic determination of baclofen in human plasma with ultraviolet detection: application to a pharmacokinetic study. J Chromatogr B Biomed Appl 487:107-115. https://doi.org/10.1016/S0378-4347(00)83012-1

15. Labat L, Goncalves A, Marques AR, Duretz B, Granger B, Declèves $X$ (2017) Liquid chromatography high resolution mass spectrometry for the determination of baclofen and its metabolites in plasma: application to therapeutic drug monitoring. Biomed Chromatogr 31:e3936. https://doi.org/10.1002/bmc.3936

16. Elagawany M, Farid NF, Elgendy B, Abdelmomen EH, Abdelwahab NS (2019) Baclofen impurities: facile synthesis and novel environmentally benign chromatographic method for their simultaneous determination in baclofen. Biomed Chromatogr 33:e4579. https://doi.org/10.1002/bmc.3936

17. Ga VNR (2018) Ultra performance liquid chromatographic seperation and quantification of baclofen and and its potential impurities in a injection formulation. IOSR-JPBS 13(4):29-38. https://doi.org/10.9790/3008-1304022938

18. ICH Harmonised Triparite Guideline (2003) Impurities in new drug substances Q3A (R2). In: Proceedings of the international conference on harmonization of technical requirements for registration of pharmaceuticals for human use, Geneva, Switzerland

19. Gloor R, Johnson EL (1977) Practical aspects off reverse phase ion pair chromatography. J Chromatogr Sci 15:413-423. https:// doi.org/10.1093/chromsci/15.9.413

20. Cai B, Li J (1999) Evaluation of trifluoroacetic acid as an ion-pair reagent in the separation of small ionizable molecules by reversedphase liquid chromatography. Anal Chim Acta 399:249-258. https://doi.org/10.1016/S0003-2670(99)00461-4

21. ICH Harmonised Triparite Guideline (2005) Validation of analytical procedures: text and methodology Q2 (R1). In: International conference on harmonization, Geneva, Switzerland

22. dos Santos J, Rosa P, Adams AIH (2018) Validation of a simple reversed phase-HPLC method for the determination of baclofen in tablets. Drug Anal Res 2:37-43. https://doi.org/10.22456/25272616.87929

23. Sanagi MM, Ling SL, Nasir Z, Hermawan D, Ibrahim WAW, Naim AA (2009) Comparison of signal-to-noise, blank determination, and linear regression methods for the estimation of detection and quantification limits for volatile organic compounds by gas chromatography. J AOAC Int 92:1833-1838. https://doi.org/10. 1093/jaoac/92.6.1833

Publisher's Note Springer Nature remains neutral with regard to jurisdictional claims in published maps and institutional affiliations. 